\title{
Construcción y validación de cuestionario de autopercepción sobre las Competencias docentes del profesorado ${ }^{1}$
}

\section{Design and validation of the self-perception questionnaire on the teaching competences of teachers}

\author{
Elena López LujÁN \\ Universidad Católica de Valencia, España \\ elena.lopez@ucv.es \\ https://orcid.org/0000-0002-2196-658X \\ Roberto Sanz Ponce ${ }^{2}$ \\ Universidad Católica de Valencia, España \\ roberto.sanz@ucv.es \\ https://orcid.org/0000-0003-1147-743X
}

\section{Resumen:}

El análisis de las competencias docentes del profesorado es una tarea preferente dentro de las políticas educativas de los diferentes países. Los docentes son una pieza clave en el éxito educativo. El objetivo de esta investigación es construir y validar un Cuestionario de autopercepción acerca de las Competencias docentes del profesorado de Educación Primaria, sustentado en el Modelo de la Acción Planificada (Ajzen y Fishbein). Para ello, partimos de un grupo de discusión y de expertos, posteriormente, realizamos los estadísticos Alfa de Cronbach, Prueba de

\begin{abstract}
:
The analysis of the teaching competences of the teaching staff is a preferred task within the educational policies of countries worldwide as teachers are a key piece in educational success. The objective of this research is to design and validate a self-perception questionnaire about the teaching competencies of primary education teachers, based on the Planned Action Model (Ajzen and Fishbein). To do this, we started from a group of discussion and a group of experts. Then, we performed the Cronbach Alpha test, the Kaiser-MeyerOlkin test and the Bartlett test of sphericity.
\end{abstract}

1 Como referenciar este artículo (How to reference this article):

López Luján, E., \& Sanz Ponce, R. (2021). Construcción y validación del cuestionario de autopercepción sobre las Competencias docentes del profesorado. Educatio Sig/o XXI, 39(3), 157-186. https://doi.org/10.6018/educatio.427461

2 Dirección para correspondencia (Correspondence address):

Roberto Sanz Ponce. Departamento de Didáctica General, Teoría de la Educación e Innovación Tecnológica. Facultad de Magisterio y Ciencias de la Educación. C/ Sagrado Corazón, 5. 46110, Godella, Valencia (España). 
Kaiser-Meyer-Olkin y Prueba de esfericidad de Bartlett. Tras estos resultados se ha construido y validado el cuestionario definitivo, con una fiabilidad 0.917 , dividido 60 ítems, con 6 factores, que responden al Modelo teórico propuesto.

\section{Palabras clave:}

Competencias docentes; Educación Primaria; Acción Planificada; Actitudes docentes.
Following the conduction of these tests, the definitive questionnaire was designed and validated, with a reliability of .917 . It comprised 60 items, divided within 6 factors which respond to the proposed theoretical model.

\section{Keywords:}

Teaching competences; Primary Education; Planned Action; Teaching attitudes.

\section{Résumé:}

L'analyse des compétences pédagogiques des enseignants est une tâche prioritaire dans les politiques éducative des enseignants du primaire, basé sur le modèle de l'action planifiée (Ajzen et Fishbein). Pour ce faire, nous avons commencé par un groupe de discussion et des experts, puis nous avons effectué les statistiques de l'alphs des différents pays. Les enseignants sont un élément clé de la réussite éducative. L'objectif de cette recherche est de construire et de valider un questionnaire d'auto-perception des compétences d'enseignementa de Cronbach, du test de Kaiser-Meyer-Olkin et du test de sphéricité de Bartlett. Suite à ces résultats, le questionnaire final a été construit et validé, avec une fiabilité de 0,917, divisé en 60 items, avec 6 facteurs, qui répondent au modèle théorique proposé.

\section{Mots clés:}

Compétences d'enseignement; Enseignement primaire; Action planifiée; Attitudes d'enseignement.

Fecha de recepción: 11-05-2020

Fecha de aceptación: 05-10-2020

\section{Introducción}

La calidad de un sistema educativo depende, en gran medida, de la calidad de sus docentes (Mourshed, Chijioke y Barber, 2012) y de la capacidad de estos para gestionar el aprendizaje, el aula y las relaciones personales y emocionales que se generan en el proceso de enseñanzaaprendizaje (Day, 2019; Hattie, 2017). Pese a esta afirmación, tanto a nivel internacional como nacional, se tiene la percepción de que los docentes se encuentran poco preparados, en téminos generales, para hacer frente a los desafíos educativos (Prats, 2016). Además, se ha instalado en la práctica pedagógica una política de rendición de cuentas -obsesión por los resultados- que limita la autonomía y la capacidad decisoria de los docentes y los convierte en meros dispensadores de curriculum (Hargreaves y Fullan, 2014). Por último, en los últimos años se han multipli- 
cado las demandas sociales y educativas a la escuela, lo que hace más compleja la tarea profesional del profesorado.

Por ello, en la actualidad las políticas educativas, tanto mundiales (OCDE, 2015) como nacionales (MECD, 2015), establecen entre sus líneas de actuación preferente las siguientes medidas: 1.- Determinar un perfil de competencias profesionales del profesorado; 2.- Adaptar la formación a dicho perfil; y 3.- Establecer una carrera profesional docente. Entre las líneas citadas destacan, por un lado, la necesidad de evaluar las competencias del profesorado, entendidas como el conjunto integrado de cualidades personales, cognitivas, pedagógicas y actitudinales necesarias para el desempeño eficaz en contextos concretos (Meirieu, 2019) y, por otro, la urgencia de diagnosticar las posibles carencias y/o necesidades docentes para elaborar planes específicos de formación inicial y continua. La formación inicial del profesorado se presenta, en este sentido, como un factor decisivo en la conformación de las competencias docentes del futuro maestro en ejercicio. La Orden ECI/3857/2007, de 27 de diciembre en la que se establecen las Competencias genéricas que debe alcanzar todo alumno de Magisterio para convertirse en maestro, da fe de ello. Sus doce competencias de carácter general describen entre otros aspectos: la necesidad de formar docentes que conozcan el curriculum de Educación Primaria y los criterios de evaluación, la necesidad de formar docentes que sean capaces de diseñar situaciones de aprendizaje pedagógicas que atiendan a la diversidad del alumnado dentro de la normalidad, la necesidad de formar docentes que sean capaces de fomentar la convivencia y la resolución pacífica de los conflictos, así como la capacidad de trabajar de manera cooperativa.

Aunque se trata de un tema no exento de polémica (Bolivar, 2019; Meirieu, 2019; Prats, 2016). Por un lado, Gairín (2011, p. 94) denuncia que en ocasiones las reformas educativas "enfatizan lo laboral, desatendiendo la parte formativa orientada a la formación de competencias personales." Por otro lado, "se detecta demasiada practicidad en las nuevas orientaciones de planes de estudio, que parecen obviar los procesos reflexivos personales o despreciar la cultura general." A esta dificultad se añade el gran número de clasificaciones sobre competencias docentes existentes (Tabla 1) que hace difícil establecer un único perfil docente y dificulta poder enumerar las cualidades necesarias para el correcto desempeño de su quehacer profesional. 
López Luján, E. y Sanz Ponce, R. (2021). Construcción y validación del cuestionario de autopercepción sobre las Competencias docentes del profesorado. Educatio Siglo XXI, 39(3), 157-186.

Tabla 1

Clasificaciones Competencias docentes

1.- Competencias intelectuales

Galvis

2.- Competencias profesionales

(2007)

3.- Competencias sociales

4.- Competencias interpersonales

5.- Competencias intrapersonales

1.- Organizar y animar situaciones de aprendizaje.

2.- Gestionar la progresión de los aprendizajes.

3.- Elaborar y hacer evolucionar dispositivos de diferenciación.

4.- Implicar a los alumnos en su aprendizaje y en su trabajo.

Perrenoud 5.- Trabajar en equipo.

(2010) 6.- Participar en la gestión de la escuela.

7.- Informar e implicar a los padres.

8.- Utilizar las nuevas tecnologías.

9.- Afrontar los deberes y los dilemas éticos de la profesión.

10.- Organizar la propia formación continua.

\begin{tabular}{|c|c|c|}
\hline \multirow{5}{*}{$\begin{array}{l}\text { Armengol, } \\
\text { Castro, } \\
\text { Jariot, } \\
\text { Massot } \\
\text { y Sala } \\
(2011)\end{array}$} & \multirow[b]{2}{*}{ Instrumentales } & Dominio de los conocimientos \\
\hline & & $\begin{array}{l}\text { Herramientas necesarias para desarrollar el ejerci- } \\
\text { cio de la práctica educativa }\end{array}$ \\
\hline & Emocionales & $\begin{array}{l}\text { Saber gestionar y regular constructivamente la } \\
\text { dimensión socioafectiva pesonal y grupal }\end{array}$ \\
\hline & \multirow[b]{2}{*}{ Sociales } & Saber colaborar con otros profesionales \\
\hline & & $\begin{array}{l}\text { Mostrar un comportamiento orientado al grupo y } \\
\text { al entendimiento interpersonal }\end{array}$ \\
\hline \multirow{11}{*}{$\begin{array}{l}\text { Consejería } \\
\text { de } \\
\text { Educación } \\
\text { de la Junta } \\
\text { de Castilla } \\
\text { y León } \\
\text { (2012) }\end{array}$} & Saber & Competencia científica \\
\hline & \multirow{2}{*}{ Saber Ser } & Competencia intrapersonal \\
\hline & & Competencia interpersonal \\
\hline & \multirow{3}{*}{$\begin{array}{l}\text { Saber Hacer } \\
\text { qué }\end{array}$} & Competencia didáctica \\
\hline & & Competencia organizativa y de gestión del centro \\
\hline & & Competencia en gestión de la convivencia \\
\hline & \multirow{4}{*}{$\begin{array}{l}\text { Saber Hacer } \\
\text { cómo }\end{array}$} & Competencia en trabajo en equipo \\
\hline & & Competencia en innovación y mejora \\
\hline & & Competencia comunicativa y lingüística \\
\hline & & Competencia digital (TIC) \\
\hline & Saber Estar & Competencia social-relacional \\
\hline \multirow{4}{*}{$\begin{array}{l}\text { Valdemo- } \\
\text { ros y Lucas } \\
(2014)\end{array}$} & \multirow{2}{*}{$\begin{array}{l}\text { Competencias } \\
\text { para Saber } \\
\text { Hacer }\end{array}$} & Competencias instrumentales \\
\hline & & Espíritu formativo \\
\hline & \multirow{2}{*}{$\begin{array}{l}\text { Competencias } \\
\text { del Saber Ser }\end{array}$} & Competencias afectivo-emocionales \\
\hline & & Personalidad docente \\
\hline
\end{tabular}




\begin{tabular}{|c|c|c|}
\hline \multirow{6}{*}{$\begin{array}{l}\text { Fernández, } \\
\text { Rodríguez } \\
\text { y Fernán- } \\
\text { dez (2016) }\end{array}$} & \multirow{3}{*}{$\begin{array}{l}\text { Competencias } \\
\text { instrumentales }\end{array}$} & $\begin{array}{l}\text { A) Conocimiento y metodología } \\
\text { Dominio de los temas; planificación; Comunica- } \\
\text { ción; Búsqueda de dinamización de los grupos; } \\
\text { Uso de recursos didácticos variados; Atención } \\
\text { individualizada de las dificultades }\end{array}$ \\
\hline & & B) Evaluativa \\
\hline & & $\begin{array}{l}\text { Uso de técnicas variadas para la evaluación: Co- } \\
\text { herencia y justicia en las correcciones y califica- } \\
\text { ciones }\end{array}$ \\
\hline & \multirow[b]{3}{*}{$\begin{array}{l}\text { Competencias } \\
\text { interpersonales }\end{array}$} & A) Individual \\
\hline & & $\begin{array}{l}\text { Actitud activa y entusiasta; Actitud motivadora y } \\
\text { de ánimo con los alumnos }\end{array}$ \\
\hline & & $\begin{array}{l}\text { B) Social } \\
\text { Fomento de un clima de confianza en el aula; } \\
\text { Corrección en el trato; Mantenimiento de la } \\
\text { disciplina }\end{array}$ \\
\hline
\end{tabular}

Por ello, el objetivo de esta investigación es construir y validar un Cuestionario de autopercepción sobre las Competencias docentes del profesorado de Educación Primaria, sustentado bajo el Modelo teórico de la Acción Planificada de Ajzen y Fishbein (1985), que nos permita diagnosticar las competencias del profesorado -Creencias, Habilidades, Actitudes, Normas subjetivas-, al mismo tiempo que nos ayude a predecir futuros comportamientos y conductas docentes -Intención de conducta y Conducta. Este último aspecto es fundamental para conocer no solo los valores y habilidades del profesorado, sino las intenciones de conducta que derivan en comportamientos. Según el Modelo de la Acción Planificada los programas de formación docente deben hacer hincapié en la modificación de las intenciones de conductas y en las conductas y no solo en los valores y las actitudes.

\section{Método}

La construcción y validación del cuestionario se ha fundamentado teóricamente sobre el Modelo de la Acción Planificada (Ajzen y Fishbein, 1985; Steinmetz, Knappstein, Ajzen, Schmidt \& Kabst, 2016). Este Modelo posibilita estudiar, de forma holística, la génesis del comportamiento de los individuos y de los grupos, medir la influencia de los diversos elementos en el comportamiento, detectar si los ítems están bien formu- 
lados y proponer orientaciones para producir cambios de conducta a nivel personal o grupal.

El procedimiento para la construcción de cuestionarios, según Ajzen y Fishbein, es el siguiente (Tabla 2).

Tabla 2

Procedimiento de construcción de cuestionarios, según Ajzen y Fishbein

\begin{tabular}{|c|c|}
\hline FASE & RESULTADOS \\
\hline Fase 1. Grupos de discusión & $\begin{array}{l}\text { Identifican los aspectos fundamentales en } \\
\text { torno a la problemática estudiada }\end{array}$ \\
\hline $\begin{array}{l}\text { Fase 2. Formulación de propo- } \\
\text { siciones }\end{array}$ & $\begin{array}{l}\text { Se redactan las proposiciones en función de } \\
\text { los comentarios del grupo de discusión }\end{array}$ \\
\hline $\begin{array}{l}\text { Fase 3. Valoración de las pro- } \\
\text { posiciones por expertos }\end{array}$ & $\begin{array}{l}\text { Valoran las proposiciones de } 1 \text { a } 10 \text { según } \\
\text { su idoneidad, pertinencia y redacción. Aña- } \\
\text { den comentarios cualitativos para perfilar las } \\
\text { proposiciones }\end{array}$ \\
\hline $\begin{array}{l}\text { Fase 4. Construcción del } \\
\text { Cuestionario-piloto }\end{array}$ & $\begin{array}{l}\text { Se elabora un cuestionario piloto y se pasa a } \\
\text { una muestra representativa }\end{array}$ \\
\hline $\begin{array}{l}\text { Fase 5. Análisis de Fiabilidad y } \\
\text { de Validez }\end{array}$ & $\begin{array}{l}\text { Evalúa la precisión de la prueba (fiabilidad) } \\
\text { y si mide lo que pretende medir (validez) }\end{array}$ \\
\hline $\begin{array}{l}\text { Fase } 6 \text {. Descripción de los } \\
\text { factores según el Modelo de la } \\
\text { Acción Planificada }\end{array}$ & $\begin{array}{l}\text { Se establecen los factores -Creencias, Habi- } \\
\text { lidades, Actitudes, Normas subjetivas, Inten- } \\
\text { ción de conducta y Conducta- mediante un } \\
\text { Análisis Factorial }\end{array}$ \\
\hline $\begin{array}{l}\text { Fase } 7 \text {. Construcción del Cues- } \\
\text { tionario definitivo }\end{array}$ & Se construye el Cuestionario definitivo \\
\hline
\end{tabular}

\section{Identificación de los factores que definen las Competencias docentes del profesorado}

Para identificar los factores que definen las Competencias docentes del profesorado se organizó un grupo de discusión (Barbour, 2013) compuesto por 10 docentes. Este grupo reflexionó sobre el tema estudiado dando sentido y significado a las proposiciones (Escámez-Marsilla, 2018). Para ello, definió el significado de Competencia docente y describió, de manera genérica, qué competencias debía tener un buen docente. Para orientar el debate se les planteó previamente la siguiente cuestión: qué conocimientos, destrezas, valores, actitudes y comportamientos debe poseer un buen docente. 


\section{Redacción y formulación de proposiciones}

La redacción y formulación de proposiciones se realizó tomando como referencia el listado de declaraciones agrupadas realizado por el grupo de discusión. Tras la redacción y formulación de proposiciones se configuró un documento compuesto por 97 ítems, divididos en 5 bloques: Conocimientos, Destrezas, Actitudes, Valores y Comportamientos.

\section{Valoración de las proposiciones por expertos}

Este documento fue valorado por un grupo de expertos, formado por 7 personas, seleccionadas por su formación académica y por su experiencia docente. Era una muestra paritaria, con diferentes perfiles ideológicos y de distintas edades. Los 7 especialistas son maestros en activo con experiencia docente amplia y sensibilizados con los temas relacionados con la formación del profesorado.

Las proposiciones debían ser valoradas entre 0 y 5 en función de tres criterios: grado de claridad e idoneidad, pertinencia de los ítems y en qué medida cada ítem medía lo que decía medir. Además, se adjuntaba un cuadro para posibles comentarios. A través de los datos obtenidos en los análisis estadísticos y de las conclusiones alcanzadas a partir de los comentarios de los expertos, valoramos la univocidad y validez de las proposiciones. Para ello realizamos un análisis descriptivo de las proposiciones -media y desviación típica- y obtuvimos el coeficiente de variación de cada una de ellas (desviación típica/media*100) (Tablas 3 y 4).

Tabla 3

Estadísticos descriptivos de cada proposición según valoración de los expertos

\begin{tabular}{cccccc}
\hline ITTEMS & N & Mínimo & Máximo & Media & Desviación Típica \\
\hline 1 & 7 & 4 & 5 & 4,57 &, 535 \\
2 & 7 & 4 & 5 & 4,86 &, 378 \\
3 & 7 & 3 & 5 & 4,29 &, 756 \\
4 & 7 & 4 & 5 & 4,71 &, 488 \\
5 & 7 & 4 & 5 & 4,57 &, 535 \\
6 & 7 & 4 & 5 & 4,71 &, 488 \\
7 & 7 & 4 & 5 & 4,86 &, 378 \\
8 & 7 & 4 & 5 & 4,86 &, 378 \\
9 & 7 & 4 & 5 & 4,86 &, 378 \\
\hline
\end{tabular}


López Luján, E. y Sanz Ponce, R. (2021). Construcción y validación del cuestionario de autopercepción sobre las Competencias docentes del profesorado. Educatio Siglo XXI, 39(3), 157-186.

\begin{tabular}{|c|c|c|c|c|c|}
\hline ITEMS & $\mathrm{N}$ & Mínimo & Máximo & Media & Desviación Típica \\
\hline 10 & 7 & 3 & 5 & 4,57 & ,787 \\
\hline 11 & 7 & 4 & 5 & 4,57 &, 535 \\
\hline 12 & 7 & 4 & 5 & 4,57 &, 535 \\
\hline 13 & 7 & 4 & 5 & 4,71 & 488 \\
\hline 14 & 7 & 3 & 5 & 4,00 & 577 \\
\hline 15 & 7 & 1 & 5 & 3,57 & 1,272 \\
\hline 16 & 7 & 4 & 5 & 4,57 &, 535 \\
\hline 17 & 7 & 1 & 5 & 3,71 & 1,380 \\
\hline 18 & 7 & 4 & 5 & 4,57 &, 535 \\
\hline 19 & 7 & 3 & 5 & 4,14 & 900 \\
\hline 20 & 7 & 4 & 5 & 4,86 &, 378 \\
\hline 21 & 7 & 4 & 5 & 4,71 & ,488 \\
\hline 22 & 7 & 4 & 5 & 4,71 & ,488 \\
\hline 23 & 7 & 4 & 5 & 4,86 &, 378 \\
\hline 24 & 7 & 4 & 5 & 4,86 & ,378 \\
\hline 25 & 7 & 3 & 5 & 4,14 & 900 \\
\hline 26 & 7 & 3 & 5 & 4,43 & ,787 \\
\hline 27 & 7 & 2 & 5 & 3,86 &, 900 \\
\hline 28 & 7 & 3 & 5 & 3,86 & 690 \\
\hline 29 & 7 & 4 & 5 & 4,71 & 488 \\
\hline 30 & 7 & 2 & 5 & 4,14 & 1,215 \\
\hline 31 & 7 & 5 & 5 & 5,00 & ,000 \\
\hline 32 & 7 & 5 & 5 & 5,00 & 000 \\
\hline 33 & 7 & 4 & 5 & 4,71 & ,488 \\
\hline 34 & 7 & 4 & 5 & 4,71 & ,488 \\
\hline 35 & 7 & 3 & 5 & 4,29 & ,756 \\
\hline 36 & 7 & 4 & 5 & 4,29 & ,488 \\
\hline 37 & 7 & 5 & 5 & 5,00 & ,000 \\
\hline 38 & 7 & 4 & 5 & 4,86 & ,378 \\
\hline 39 & 7 & 4 & 5 & 4,71 & ,488 \\
\hline 40 & 7 & 4 & 5 & 4,86 & ,378 \\
\hline 41 & 7 & 4 & 5 & 4,29 & ,488 \\
\hline 42 & 7 & 4 & 5 & 4,86 & ,378 \\
\hline 43 & 7 & 3 & 5 & 4,29 & ,756 \\
\hline 44 & 7 & 4 & 5 & 4,86 &, 378 \\
\hline 45 & 7 & 4 & 5 & 4,71 & ,488 \\
\hline
\end{tabular}




\begin{tabular}{|c|c|c|c|c|c|}
\hline ÍTEMS & $\mathrm{N}$ & Mínimo & Máximo & Media & Desviación Típica \\
\hline 46 & 7 & 4 & 5 & 4,86 & ,378 \\
\hline 47 & 7 & 5 & 5 & 5,00 &, 000 \\
\hline 48 & 7 & 5 & 5 & 5,00 & ,000 \\
\hline 49 & 7 & 4 & 5 & 4,71 & ,488 \\
\hline 50 & 7 & 4 & 5 & 4,71 & ,488 \\
\hline 51 & 7 & 5 & 5 & 5,00 &, 000 \\
\hline 52 & 7 & 4 & 5 & 4,86 & ,378 \\
\hline 53 & 7 & 2 & 5 & 4,00 & 1,155 \\
\hline 54 & 7 & 4 & 5 & 4,57 &, 535 \\
\hline 55 & 7 & 4 & 5 & 4,57 &, 535 \\
\hline 56 & 7 & 1 & 5 & 3,57 & 1,902 \\
\hline 57 & 7 & 1 & 5 & 3,57 & 1,397 \\
\hline 58 & 7 & 0 & 5 & 4,29 & 1,890 \\
\hline 59 & 7 & 0 & 5 & 4,00 & 1,826 \\
\hline 60 & 7 & 4 & 5 & 4,43 &, 535 \\
\hline 61 & 7 & 4 & 5 & 4,86 & ,378 \\
\hline 62 & 7 & 3 & 5 & 4,14 &, 900 \\
\hline 63 & 7 & 1 & 5 & 4,14 & 1,574 \\
\hline 64 & 7 & 3 & 5 & 4,29 &, 951 \\
\hline 65 & 7 & 1 & 5 & 4,00 & 1,528 \\
\hline 66 & 7 & 3 & 5 & 4,57 & ,787 \\
\hline 67 & 7 & 5 & 5 & 5,00 & ,000 \\
\hline 68 & 7 & 5 & 5 & 5,00 & ,000 \\
\hline 69 & 7 & 5 & 5 & 5,00 & 000 \\
\hline 70 & 7 & 5 & 5 & 5,00 &, 000 \\
\hline 71 & 7 & 5 & 5 & 5,00 & ,000 \\
\hline 72 & 7 & 5 & 5 & 5,00 &, 000 \\
\hline 73 & 7 & 5 & 5 & 5,00 & ,000 \\
\hline 74 & 7 & 1 & 5 & 4,43 & 1,512 \\
\hline 75 & 7 & 5 & 5 & 5,00 & ,000 \\
\hline 76 & 7 & 4 & 5 & 4,71 & ,488 \\
\hline 77 & 7 & 4 & 5 & 4,86 &, 378 \\
\hline 78 & 7 & 4 & 5 & 4,71 & ,488 \\
\hline 79 & 7 & 3 & 5 & 4,43 & ,787 \\
\hline 80 & 7 & 1 & 5 & 3,71 & 1,890 \\
\hline 81 & 7 & 4 & 5 & 4,71 & 488 \\
\hline
\end{tabular}




\begin{tabular}{cccccc}
\hline ITEMS & N & Mínimo & Máximo & Media & Desviación Típica \\
\hline 82 & 7 & 1 & 5 & 4,14 & 1,464 \\
$\mathbf{8 3}$ & 7 & $\mathbf{1}$ & $\mathbf{5}$ & $\mathbf{3 , 2 9}$ & $\mathbf{1 , 3 8 0}$ \\
84 & 7 & 4 & 5 & 4,43 &, 535 \\
$\mathbf{8 5}$ & 7 & $\mathbf{1}$ & $\mathbf{5}$ & $\mathbf{4 , 0 0}$ & $\mathbf{1 , 4 1 4}$ \\
86 & 7 & 3 & 5 & 4,43 &, 787 \\
87 & 7 & 4 & 5 & 4,71 &, 488 \\
$\mathbf{8 8}$ & 7 & $\mathbf{2}$ & $\mathbf{5}$ & $\mathbf{3 , 7 1}$ &, $\mathbf{9 5 1}$ \\
89 & 7 & 3 & 5 & 4,14 &, 900 \\
$\mathbf{9 0}$ & 7 & $\mathbf{2}$ & $\mathbf{5}$ & $\mathbf{3 , 7 1}$ & $\mathbf{1 , 3 8 0}$ \\
91 & 7 & 3 & 5 & 4,71 &, 756 \\
$\mathbf{9 2}$ & 7 & $\mathbf{3}$ & $\mathbf{5}$ & $\mathbf{4 , 0 0}$ & $\mathbf{1 , 0 0 0}$ \\
$\mathbf{9 3}$ & 7 & $\mathbf{0}$ & $\mathbf{5}$ & $\mathbf{4 , 0 0}$ & $\mathbf{1 , 8 2 6}$ \\
$\mathbf{9 4}$ & $\mathbf{7}$ & $\mathbf{0}$ & $\mathbf{5}$ & $\mathbf{4 , 0 0}$ & $\mathbf{1 , 8 2 6}$ \\
95 & 7 & 4 & 5 & 4,86 &, 378 \\
96 & 7 & 4 & 5 & 4,57 &, 535 \\
97 & 7 & 4 & 5 & 4,86 &, 378 \\
Valid N (listwise) & 7 & & & &
\end{tabular}

Tabla 4

Coeficiente de variación de cada proposición según valoración de los expertos

\begin{tabular}{|c|c|c|c|c|c|}
\hline No ÍTEM & Coef. Variación & jo ÍTEM & Coef. Variación & $\mathrm{N}^{\mathrm{o}}$ ÍTEM & Coef. Variación \\
\hline 1 & 0,117067834 & 34 & 0,103609342 & 67 & 0 \\
\hline 2 & 0,077777778 & 35 & 0,176223776 & 68 & 0 \\
\hline 3 & 0,176223776 & 36 & 0,113752914 & 69 & 0 \\
\hline 4 & 0,103609342 & 37 & 0 & 70 & 0 \\
\hline 5 & 0,117067834 & 38 & 0,077777778 & 71 & 0 \\
\hline 6 & 0,103609342 & 39 & 0,103609342 & 72 & 0 \\
\hline 7 & 0,077777778 & 40 & 0,077777778 & 73 & 0 \\
\hline 8 & 0,077777778 & 41 & 0,113752914 & 74 & 0,341309255 \\
\hline 9 & 0,077777778 & 42 & 0,077777778 & 75 & 0 \\
\hline 10 & 0,172210066 & 43 & 0,176223776 & 76 & 0,103609342 \\
\hline 11 & 0,117067834 & 44 & 0,077777778 & 77 & 0,077777778 \\
\hline 12 & 0,117067834 & 45 & 0,103609342 & 78 & 0,103609342 \\
\hline 13 & 0,103609342 & 46 & 0,077777778 & 79 & 0,17765237 \\
\hline 14 & 0,14425 & 47 & 0 & 80 & 0,509433962 \\
\hline 15 & 0,356302521 & 48 & 0 & 81 & 0,103609342 \\
\hline
\end{tabular}




\begin{tabular}{|c|c|c|c|c|c|}
\hline No ÍTEM & Coef. Variación & Vo ÍTEM & Coef. Variación & o ÍTEM & Coef. Variación \\
\hline 16 & 0,117067834 & 49 & 0,103609342 & 82 & 0,353623188 \\
\hline 17 & 0,371967655 & 50 & 0,103609342 & 83 & 0,419452888 \\
\hline 18 & 0,117067834 & 51 & 0 & 84 & 0,120767494 \\
\hline 19 & 0,217391304 & 52 & 0,077777778 & 85 & 0,3535 \\
\hline 20 & 0,077777778 & 53 & 0,28875 & 86 & 0,17765237 \\
\hline 21 & 0,103609342 & 54 & 0,117067834 & 87 & 0,103609342 \\
\hline 22 & 0,103609342 & 55 & 0,117067834 & 88 & 0,256334232 \\
\hline 23 & 0,077777778 & 56 & 0,532773109 & 89 & 0,217391304 \\
\hline 24 & 0,077777778 & 57 & 0,391316527 & 90 & 0,371967655 \\
\hline 25 & 0,217391304 & 58 & 0,440559441 & 91 & 0,160509554 \\
\hline 26 & 0,17765237 & 59 & 0,4565 & 92 & 0,25 \\
\hline 27 & 0,233160622 & 60 & 0,120767494 & 93 & 0,4565 \\
\hline 28 & 0,178756477 & 61 & 0,077777778 & 94 & 0,4565 \\
\hline 29 & 0,103609342 & 62 & 0,217391304 & 95 & 0,077777778 \\
\hline 30 & 0,293478261 & 63 & 0,380193237 & 96 & 0,117067834 \\
\hline 31 & 0 & 64 & 0,221678322 & 97 & 0,077777778 \\
\hline 32 & 0 & 65 & 0,382 & & \\
\hline 33 & 0,103609342 & 66 & 0,172210066 & & \\
\hline
\end{tabular}

Por otro lado, también se tuvieron en cuenta los cometarios realizados por los expertos:

1) Bloque de Conocimientos

El experto 1 señala la necesidad de agrupar los ítems 2-5, 6-7, 10 11 y 21-22. El experto 4 pide incluir ítems que predigan la capacidad del trabajo en equipo, la identificación de las necesidades del aula y la capacidad para crear entornos inclusivos. El experto 7 solicita incluir aspectos relacionados con el descubrimiento de los niños de su identidad personal y social.

2) Bloque de Destrezas

El experto 1 recomienda agrupar los ítems 37-38 y 40-45 y el experto 7 los ítems 42-49-50 y 40-45.

3) Bloque de Actitudes

El experto 1 recomienda agrupar los ítems 58-59 y 62-64 y el experto 7, el 57-62.

4) Bloque de Valores

El experto 1 recomienda agrupar los ítems 65-66 y el experto 7 reformula el ítem 80: "Cree que el aprendizaje se adquiere con el 
esfuerzo del alumnado, profesorado y las familias o tutores legales".

5) Bloque de Comportamientos

El experto 7 recomienda agrupar los ítems 83-84 y añadir la palabra: "familias" en el ítem 87 y "mediación" en el 91.

Tras el análisis cuantitativo y cualitativo de las proposiciones procedimos a la eliminación o reformulación de algunos de los enunciados. El criterio de eliminación fue que tuvieran una media inferior a 4 o que el coeficiente de variación tuviera altos niveles de discrepancia, es decir, una variación superior a 25\%. Se eliminaron los ítems: 3, 4, 14, 15, 17, $27,28,30,53,56,57,58,65,74,80,83,85,88,90,92$ y 93. Se agruparon los ítems: 2, 5, 6, 7, 10, 11, 21, 22, 25, 29, 37, 38, 40, 42, 45, 49, 50, 62, 64. Se reformularon los ítems: 86 y 91 . Y se decidió mantener los ítems: 59, 63, 82 y 94 .

\section{Construcción del Cuestionario: prueba piloto}

A partir de las valoraciones de los expertos se elaboró un cuestionariopiloto. Este cuestionario-piloto quedó confeccionado por un total de 65 ítems, todos ellos de respuesta tipo Likert. Se aplicó a una muestra de 154 docentes de centros públicos y concertados de Valencia, se analizaron las respuestas con el programa SPSS-23 y se depuró el cuestionario.

\section{Resultados}

\section{Análisis de Fiabilidad}

Un cuestionario es fiable si es capaz de obtener respuestas semejantes ante circunstancias y momentos semejantes o, por el contrario, cuando es capaz de producir respuestas diferentes en personas con distintas circunstancias.

La fiabilidad nos da información sobre la precisión de la prueba como instrumento de medida independientemente de lo que pretenda medir. La fiabilidad perfecta es Rxx=1, por ello, cuanto más se aproxima a 1 el valor que obtengamos mayor será su fiabilidad. En nuestro caso, la consistencia interna se midió a través del Alfa de Cronbach. Este Coeficiente, 
para que se considere aceptable, debe estar por encima de 0,60 , siendo recomendable que sea mayor de 0,75 (Morales, Urosa y Blanco, 2003).

En nuestro estudio, se hizo un primer acercamiento a la fiabilidad del cuestionario-piloto obteniendo un resultado muy alto (Tabla 5). A pesar de ello, se procedió a la eliminación de aquellos ítems que presentaban un resultado bajo o negativo (Tabla 6).

Tabla 5

Estadísticas de fiabilidad. Fuente: SPSS-23

\begin{tabular}{cc}
\hline Alfa de Cronbach & $\mathrm{N}$ de elementos \\
\hline, 894 & 65 \\
\hline
\end{tabular}

Tabla 6

Estadísticas de total de elemento. Fuente: SPSS-23

\begin{tabular}{ccc}
\hline Ítem & $\begin{array}{c}\text { Correlación total de } \\
\text { elementos corregida }\end{array}$ & $\begin{array}{c}\text { Alfa de Cronbach si el } \\
\text { elemento se ha suprimido }\end{array}$ \\
\hline 1 &, 331 &, 892 \\
2 &, 274 &, 893 \\
3 &, 295 &, 893 \\
4 &, 303 &, 892 \\
5 &, 606 &, 888 \\
6 &, 635 &, 889 \\
$\mathbf{7}$ & $\mathbf{- 5 1 3}$ & $\mathbf{9 0 2}$ \\
$\mathbf{8}$ & $\mathbf{- 5 1 9}$ & $\mathbf{9 0 4}$ \\
9 &, 342 &, 892 \\
10 &, 301 &, 892 \\
$\mathbf{1 1}$ & $\mathbf{0 2 6}$ & $\mathbf{8 9 7}$ \\
12 &, 255 &, 893 \\
13 &, 271 &, 893 \\
14 &, 400 &, 892 \\
15 &, 522 &, 890 \\
16 &, 313 &, 892 \\
17 &, 334 &, 892 \\
18 &, 421 &, 891 \\
19 &, 512 &, 890 \\
20 &, 322 &, 892 \\
21 &, 393 &, 892 \\
22 &, 310 &, 892 \\
23 &, 434 &, 891 \\
24 &, 471 &, 891 \\
25 &, 497 &, 891 \\
\hline
\end{tabular}


López Luján, E. y Sanz Ponce, R. (2021). Construcción y validación del cuestionario de autopercepción sobre las Competencias docentes del profesorado. Educatio Siglo XXI, 39(3), 157-186.

\begin{tabular}{|c|c|c|}
\hline Ítem & $\begin{array}{l}\text { Correlación total de } \\
\text { elementos corregida }\end{array}$ & $\begin{array}{c}\text { Alfa de Cronbach si el } \\
\text { elemento se ha suprimido }\end{array}$ \\
\hline 26 & 315 & ,892 \\
\hline 27 & 159 & 894 \\
\hline 28 & ,337 & ,892 \\
\hline 29 & ,388 & ,892 \\
\hline 30 & ,390 & ,892 \\
\hline 31 & 623 & 889 \\
\hline 32 & ,272 & 893 \\
\hline 33 & ,340 & 892 \\
\hline 34 & 256 & ,893 \\
\hline 35 & ,359 & ,892 \\
\hline 36 & ,462 & 891 \\
\hline 37 & 603 & 888 \\
\hline 38 & 252 & 893 \\
\hline 39 & 380 & ,892 \\
\hline 40 & 614 & 888 \\
\hline 41 & 485 & 891 \\
\hline 42 & ,332 & ,892 \\
\hline 43 & 264 & ,893 \\
\hline 44 & ,241 & ,893 \\
\hline 45 & ,181 & 894 \\
\hline 46 & ,341 & ,893 \\
\hline 47 & 627 & 888 \\
\hline 48 & ,104 & 897 \\
\hline 49 & ,064 & 894 \\
\hline 50 &,- 104 & 896 \\
\hline 51 & 347 & ,892 \\
\hline 52 & ,352 & 892 \\
\hline 53 & ,352 & ,892 \\
\hline 54 & ,419 & 891 \\
\hline 55 & ,227 & ,893 \\
\hline 56 & ,070 & ,897 \\
\hline 57 & ,509 & 890 \\
\hline 58 & ,519 & 890 \\
\hline 59 & ,438 & 891 \\
\hline 60 &, 445 & ,891 \\
\hline 61 & 408 & 891 \\
\hline 62 & 349 & ,892 \\
\hline 63 & 620 & ,888 \\
\hline 64 & 345 & ,892 \\
\hline 65 & ,459 & ,891 \\
\hline
\end{tabular}


Tras los análisis realizados se encontraron ítems con una correlación baja o negativa: 7, 8, 11, 49 y 50. Tras eliminar estos ítems, el Alfa de Cronbach subió hasta un .917.

\section{Análisis de validez}

La validez analiza si la prueba mide lo que pretende medir. Para comprobar la validez del cuestionario se utilizó el análisis factorial, que nos permite conocer las interrelaciones entre un conjunto de variables, agrupando aquellos ítems que miden el mismo rasgo. Antes de acometer el análisis factorial se realizaron las pruebas de esfericidad de Barlett y de Kaiser-Meyer-Olkin (KMO) (Tabla 7).

Tabla 7

Prueba de KMO y Bartlett. Fuente: SPSS-23

Medida Kaiser-Meyer-Olkin de adecuación de muestreo , 757

Prueba de esfericidad de Bartlett

\begin{tabular}{lr} 
Aprox. Chi-cuadrado & 7844,043 \\
\hline Gl & 1770 \\
\hline Sig. &, 000
\end{tabular}

El valor $K M O$ de nuestro cuestionario es 0,757 , por lo que es posible llevar a cabo un análisis factorial (Tabla 8).

Tabla 8

Matriz de componentes principales. ${ }^{a}$ Fuente: SPSS-23

\begin{tabular}{lcccccc}
\hline \multirow{2}{*}{ ITEMS } & \multicolumn{7}{c}{ Componente } \\
\cline { 2 - 6 } & 1 & 2 & 3 & 4 & 5 & 6 \\
\hline 6. &, 733 &,- 487 &, 293 &, 191 &, 085 &,- 056 \\
5. &, 715 &,- 519 &, 228 &, 207 &, 144 &,- 008 \\
63. &, 705 &,- 331 &,- 258 &,- 084 &,- 130 &,- 225 \\
31. &, 705 &,- 335 &,- 329 &,- 210 &,- 205 &,- 076 \\
47. &, 694 &,- 260 &,- 377 &,- 087 &,- 205 &,- 101 \\
37. &, 690 &,- 289 &,- 334 &,- 311 &,- 230 &,- 085 \\
40. &, 689 &,- 292 &,- 378 &,- 059 &,- 182 &,- 107 \\
15. &, 629 &,- 403 &,- 086 &,- 363 &,- 180 &,- 038 \\
58. &, 604 &,- 428 &, 096 &, 313 &, 191 &,- 096 \\
25. &, 598 &,- 442 &, 082 &,- 376 &, 112 &, 069 \\
65. &, 567 &,- 456 &, 453 &, 019 &, 190 &,- 010 \\
19. &, 558 &,- 220 &,- 415 &, 231 &, 114 &,- 130 \\
57. &, 504 &, 361 &,- 182 &,- 017 &,- 080 &,- 094 \\
\hline
\end{tabular}


López Luján, E. y Sanz Ponce, R. (2021). Construcción y validación del cuestionario de autopercepción sobre las Competencias docentes del profesorado. Educatio Siglo XXI, 39(3), 157-186.

\begin{tabular}{|c|c|c|c|c|c|c|}
\hline \multirow{2}{*}{ ÍTEMS } & \multicolumn{6}{|c|}{ Componente } \\
\hline & 1 & 2 & 3 & 4 & 5 & 6 \\
\hline 41. &, 500 & 297 &,- 093 & 169 &,- 121 & 143 \\
\hline 36. & ,472 & ,307 & ,061 &,- 029 &,- 306 &,- 112 \\
\hline 23. & 439 & ,313 &,- 104 &,- 227 & ,385 & 153 \\
\hline 59. & ,432 & ,397 & ,067 &, 116 &,- 047 &,- 211 \\
\hline 18. & ,413 & ,314 &,- 088 &,- 183 & ,006 &,- 379 \\
\hline 30. & ,412 & ,339 &,- 052 &,- 282 &,- 091 &,- 052 \\
\hline 54. & ,397 & ,328 & ,312 &, 273 &,- 006 &,- 094 \\
\hline 39. & ,389 & ,295 &,- 175 &,- 128 &,- 167 & 263 \\
\hline 42. & ,362 & ,089 &,- 118 &,- 140 & ,292 & , 132 \\
\hline 35. & ,359 & ,342 &,- 012 &,- 137 &,- 272 &,- 096 \\
\hline 64. &, 357 & ,291 & ,031 & ,073 &,- 113 & ,224 \\
\hline 20. & ,349 & ,040 & ,047 &,- 036 & ,237 &,- 241 \\
\hline 51. & 347 &, 250 &,- 107 & 129 &,- 103 & 147 \\
\hline 9. & ,345 & ,232 & , 107 & ,046 & , 161 &,- 053 \\
\hline 4. & ,320 & , 152 & 267 &,- 061 & 153 &,- 090 \\
\hline 16. & ,308 &, 159 &,- 175 & ,039 & 164 & ,074 \\
\hline 21. & ,359 & ,563 & ,026 &,- 102 &,- 105 &,- 160 \\
\hline 61. & 399 & ,539 & 162 & 081 &,- 227 & 103 \\
\hline 43. & ,378 &,- 526 & ,512 & ,045 &,- 165 & , 166 \\
\hline 32. & 383 &,- 516 &, 514 & 040 &,- 162 & , 167 \\
\hline 53. & ,476 &,- 514 & ,447 &,- 095 &,- 135 & ,279 \\
\hline 52. &, 476 &,- 502 & ,440 &,- 104 &,- 143 & ,284 \\
\hline 1. & 303 & ,494 & ,326 & ,258 & ,037 &,- 058 \\
\hline 2. & 241 & ,489 & ,249 & ,128 & , 166 &,- 093 \\
\hline 62. & 340 & 472 & ,029 &,- 113 &,- 064 & ,282 \\
\hline 33. & ,326 & ,465 & ,130 &,- 073 & ,075 & ,351 \\
\hline 17. & 305 & 452 & ,145 & ,051 & ,317 &,- 268 \\
\hline 60. &, 434 & ,437 & 073 & ,191 &,- 180 & ,085 \\
\hline 29. & ,398 & ,436 & ,145 & ,107 &,- 109 & 079 \\
\hline 28. & ,352 & 420 & 125 &,- 181 &,- 234 & ,202 \\
\hline 10. & 283 & ,405 & ,246 & ,325 & 123 &,- 109 \\
\hline 46. & ,354 & ,391 & ,054 &,- 066 &,- 044 & ,226 \\
\hline 3. & ,280 & ,365 & 274 & , 192 & ,130 &,- 213 \\
\hline 56. & ,087 &,- 038 &,- 467 & ,404 & 082 & ,245 \\
\hline 44. & ,311 &,- 270 & ,408 & 220 & 195 &,- 265 \\
\hline 55. & ,279 &,- 123 & 293 & 140 & 204 &,- 256 \\
\hline 26. & ,342 &,- 052 &,- 387 & 603 & ,066 & 249 \\
\hline 22. & ,341 &,- 227 &,- 475 & ,589 & ,052 & ,051 \\
\hline 12. & ,299 &,- 226 &,- 536 & ,548 &, 046 & 071 \\
\hline
\end{tabular}




\begin{tabular}{ccccccc}
\hline \multirow{2}{*}{ ÍTEMS } & \multicolumn{7}{c}{ Componente } \\
\cline { 2 - 6 } & 1 & 2 & 3 & 4 & 5 & 6 \\
\hline 24. &, 486 &, 219 &,- 157 &,- 359 &, 490 &, 006 \\
14. &, 424 &, 006 &,- 385 &,- 317 &, 454 &, 157 \\
48. &, 137 &,- 101 &,- 189 &,- 271 &, 391 &,- 214 \\
13. &, 282 &, 158 &,- 064 &,- 251 &, 387 &, 263 \\
38. &, 257 &, 172 &,- 215 &, 147 &,- 294 &,- 122 \\
34. &, 259 &, 147 &, 048 &, 043 &, 172 &, 526 \\
27. &, 165 &, 267 &, 057 &,- 049 &,- 247 &,- 315 \\
\hline
\end{tabular}

Extraction Method: Principal Component Analysis.

a. 6 components extracted.

Posteriormente se realizó una rotación varimax para obtener los factores que subyacen de la estructura del cuestionario. Como procedimiento se deben eliminar aquellos ítems con saturaciones bajas en algún factor o aquellos otros que saturan en más de uno, consiguiendo una estructura factorial limpia, donde cada ítem satura únicamente en un factor y siempre por encima de 0,300 (Tabla 9).

Tabla 9

Matriz de componente rotado de 60 ítems. ${ }^{a}$ Fuente: SPSS-23

\begin{tabular}{lcccccc}
\hline \multirow{2}{*}{ ITEMS } & \multicolumn{7}{c}{ Componente } \\
\cline { 2 - 6 } & 1 & 2 & 3 & 4 & 5 & 6 \\
\hline 53. &, 872 &, 119 &, 047 &,- 122 &,- 069 &, 004 \\
52. &, 862 &, 132 &, 052 &,- 129 &,- 073 &, 006 \\
43. &, 843 &, 025 &, 012 &,- 022 &,- 049 &,- 158 \\
32. &, 840 &, 034 &, 012 &,- 017 &,- 054 &,- 151 \\
6. &, 832 &,- 010 &, 252 &, 277 &, 254 &, 104 \\
5. &, 817 &,- 042 &, 216 &, 233 &, 318 &, 157 \\
65. &, 816 &,- 067 &, 079 &, 254 &, 012 &, 171 \\
25. &, 635 &,- 001 &, 337 &,- 106 &,- 067 &, 431 \\
58. &, 614 &,- 110 &, 203 &, 289 &, 414 &, 129 \\
44. &, 492 &,- 200 &, 033 &, 456 &, 039 &,- 030 \\
61. &,- 016 &, 673 &, 083 &, 285 &,- 026 &,- 055 \\
28. &, 031 &, 628 &, 108 &, 051 &,- 173 &, 068 \\
62. &,- 044 &, 621 &,- 003 &, 070 &,- 046 &, 200 \\
33. &, 020 &, 602 &,- 158 &, 131 &,- 043 &, 261 \\
60. &, 016 &, 589 &, 108 &, 286 &, 134 &,- 047 \\
29. &, 032 &, 550 &, 058 &, 302 &, 030 &, 012 \\
46. &, 015 &, 544 &, 015 &, 110 &,- 015 &, 175 \\
\hline
\end{tabular}


López Luján, E. y Sanz Ponce, R. (2021). Construcción y validación del cuestionario de autopercepción sobre las Competencias docentes del profesorado. Educatio Siglo XXI, 39(3), 157-186.

\begin{tabular}{|c|c|c|c|c|c|c|}
\hline \multirow{2}{*}{ ÍTEMS } & \multicolumn{6}{|c|}{ Componente } \\
\hline & 1 & 2 & 3 & 4 & 5 & 6 \\
\hline 39. &,- 020 & 544 & 183 &,- 100 & 081 & 190 \\
\hline 41. & 059 &, 522 &, 173 &, 163 & ,268 & ,076 \\
\hline 64. & 071 &, 502 & ,030 & ,090 & , 109 & 058 \\
\hline 21. &,- 189 & ,487 & ,263 & ,350 &,- 137 & 101 \\
\hline 36. & ,066 & ,477 &, 374 & ,226 &,- 045 &,- 060 \\
\hline 35. &,- 054 & 438 & ,349 & ,138 &,- 113 & ,002 \\
\hline 57. &,- 084 & 429 & ,371 & 231 & 129 & 184 \\
\hline 51. & ,002 & 417 & 109 & ,083 & ,217 & ,057 \\
\hline 30. &,- 043 & ,412 & ,330 & ,122 &,- 153 & ,241 \\
\hline 34. & 179 & ,409 &,- 292 &,- 067 & , 171 & ,285 \\
\hline 37. & ,339 &, 154 & ,744 &,- 202 & 135 & ,280 \\
\hline 31. & ,382 &, 126 & ,711 &,- 171 & ,224 & ,251 \\
\hline 63. & ,385 & ,031 & ,701 & ,019 & ,259 & ,201 \\
\hline 47. & ,300 &, 150 & ,695 &,- 104 &, 321 & 203 \\
\hline 40. & ,315 &, 115 & ,684 &,- 096 & ,349 & ,202 \\
\hline 15. &, 520 & ,080 & ,595 &,- 191 &,- 021 & ,252 \\
\hline 18. &,- 119 & , 197 &, 466 &, 356 &,- 106 & ,216 \\
\hline 38. &,- 108 & 256 & ,346 & 073 & 204 &,- 146 \\
\hline 27. &,- 116 & ,189 & ,323 & 247 &,- 162 &,- 152 \\
\hline 45. & 031 & ,031 & ,321 & ,096 & 010 &,- 052 \\
\hline 17. &,- 114 & 190 & 043 & 611 &,- 051 & ,259 \\
\hline 3. & 017 & 228 &,- 001 & ,577 &,- 022 & ,013 \\
\hline 10. & ,004 & ,304 &,- 086 &, 571 & ,105 &,- 025 \\
\hline 1. & 013 & ,434 &,- 093 &, 560 & ,000 &,- 056 \\
\hline 54. & ,152 &, 370 & ,014 &, 526 & ,060 &,- 076 \\
\hline 2. &,- 070 & ,333 &,- 091 & ,525 &,- 059 & ,094 \\
\hline 59. &,- 034 & ,368 & 248 & ,456 & ,047 & ,034 \\
\hline 55. & ,321 &,- 129 & ,058 & 425 & ,012 & ,047 \\
\hline 4. & ,189 & , 166 & ,038 & ,345 &,- 132 & , 175 \\
\hline 20. & 120 &,- 016 & ,197 &, 344 & ,015 & ,261 \\
\hline 9. & 075 & 228 & ,051 & ,341 & ,036 & 194 \\
\hline 22. & ,085 &,- 031 &, 173 & ,028 & 840 &,- 001 \\
\hline 12. & ,034 &,- 043 & , 178 &,- 038 & 836 & ,020 \\
\hline 26. & ,066 & 179 &,- 006 & ,030 & 813 & ,025 \\
\hline 56. &,- 123 & 059 &,- 053 &,- 138 & ,643 & ,066 \\
\hline 19. & , 176 &,- 028 & ,432 & 108 &, 570 & ,245 \\
\hline 14. & ,025 & ,078 & 170 &,- 078 & 172 & ,767 \\
\hline 24. & 011 & , 175 & 167 & 200 &,- 029 & ,761 \\
\hline 23. &,- 007 & 326 & ,035 & ,173 & ,027 & ,621 \\
\hline
\end{tabular}




\begin{tabular}{ccccccc}
\hline \multirow{2}{*}{ ÍTEMS } & \multicolumn{7}{c}{ Componente } \\
\cline { 2 - 6 } & 1 & 2 & 3 & 4 & 5 & 6 \\
\hline 13. &, 055 &, 212 &,- 097 &, 013 &,- 005 &, 577 \\
48. &,- 030 &,- 264 &, 188 &, 082 &,- 036 &, 473 \\
42. &, 086 &, 170 &, 056 &, 069 &, 101 &, 469
\end{tabular}

Extraction Method: Principal Component Analysis.

Rotation Method: Varimax with Kaiser Normalization.

a. Rotation converged in 6 iterations.

Por último, obtuvimos un Análisis Factorial que identifica 6 factores, que explican una varianza de 50,911\% (Tabla 10).

Tabla 10

Varianza total explicada. Fuente: SPSS-23

\begin{tabular}{|c|c|c|c|c|c|c|c|c|c|}
\hline \multirow[b]{2}{*}{$\sum_{\stackrel{E}{E}}^{n}$} & \multicolumn{3}{|c|}{ Autovalores iniciales } & \multicolumn{3}{|c|}{$\begin{array}{l}\text { Sumas de extracción } \\
\text { de cargas al cuadrado }\end{array}$} & \multicolumn{3}{|c|}{$\begin{array}{c}\text { Sumas de rotación } \\
\text { de cargas al cuadrado }\end{array}$} \\
\hline & $\overline{\frac{\pi}{0}}$ & 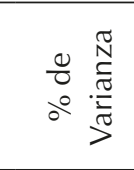 & $\circ \frac{\frac{0}{0}}{\frac{\pi}{\vec{g}}}$ & 퓽 & 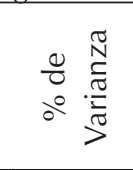 & $\circ \frac{\frac{0}{\sigma}}{\frac{\pi}{\vec{\sigma}}}$ & $\begin{array}{l}\overline{\widetilde{\sigma}} \\
\stackrel{0}{0}\end{array}$ & 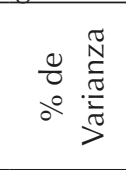 & 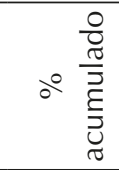 \\
\hline 1 & 11,398 & 18,997 & 18,997 & 11,398 & 18,997 & 18,997 & 7,245 & 12,075 & 12,075 \\
\hline 2 & 7,317 & 12,195 & 31,192 & 7,317 & 12,195 & 31,192 & 6,242 & 10,403 & 22,478 \\
\hline 3 & 4,189 & 6,981 & 38,174 & 4,189 & 6,981 & 38,174 & 4,973 & 8,289 & 30,766 \\
\hline 4 & 3,037 & 5,061 & 43,235 & 3,037 & 5,061 & 43,235 & 4,241 & 7,068 & 37,834 \\
\hline 5 & 2,433 & 4,055 & 47,290 & 2,433 & 4,055 & 47,290 & 4,026 & 6,710 & 44,544 \\
\hline 6 & 2,172 & 3,621 & 50,911 & 2,172 & 3,621 & 50,911 & 3,820 & 6,367 & 50,911 \\
\hline 7 & 2,031 & 3,384 & 54,295 & & & & & & \\
\hline 8 & 1,754 & 2,924 & 57,219 & & & & & & \\
\hline 9 & 1,607 & 2,678 & 59,897 & & & & & & \\
\hline 10 & 1,569 & 2,615 & 62,512 & & & & & & \\
\hline 11 & 1,402 & 2,337 & 64,850 & & & & & & \\
\hline 12 & 1,346 & 2,244 & 67,093 & & & & & & \\
\hline 13 & 1,216 & 2,027 & 69,120 & & & & & & \\
\hline 14 & 1,137 & 1,895 & 71,015 & & & & & & \\
\hline 15 & 1,071 & 1,785 & 72,800 & & & & & & \\
\hline 16 & 1,023 & 1,704 & 74,505 & & & & & & \\
\hline 17 & ,968 & 1,613 & 76,118 & & & & & & \\
\hline 18 & ,919 & 1,532 & 77,650 & & & & & & \\
\hline 19 & ,868 & 1,447 & 79,097 & & & & & & \\
\hline 20 & 841 & 1,402 & 80,500 & & & & & & \\
\hline 21 & 809 & 1,348 & 81,848 & & & & & & \\
\hline
\end{tabular}


López Luján, E. y Sanz Ponce, R. (2021). Construcción y validación del cuestionario de autopercepción sobre las Competencias docentes del profesorado. Educatio Siglo XXI, 39(3), 157-186.

\begin{tabular}{|c|c|c|c|c|c|c|c|c|c|}
\hline \multirow[b]{2}{*}{$\sum_{\underline{E}}^{\infty}$} & \multicolumn{3}{|c|}{ Autovalores iniciales } & \multicolumn{3}{|c|}{$\begin{array}{l}\text { Sumas de extracción } \\
\text { de cargas al cuadrado }\end{array}$} & \multicolumn{3}{|c|}{$\begin{array}{c}\text { Sumas de rotación } \\
\text { de cargas al cuadrado }\end{array}$} \\
\hline & సٓㅠㅇ & 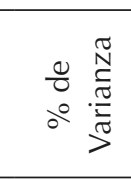 & 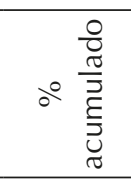 & 胥 & $\frac{\sqrt{N}}{0} \frac{\stackrel{\pi}{\frac{\pi}{2}}}{\circ}$ & 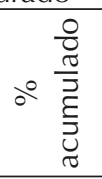 & 胥 & $\frac{\sqrt{\frac{\pi}{N}}}{0} \frac{\stackrel{\frac{\pi}{2}}{\frac{\pi}{2}}}{\circ}$ & 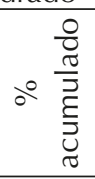 \\
\hline 22 & ,766 & 1,276 & 83,124 & & & & & & \\
\hline 23 & ,735 & 1,225 & 84,349 & & & & & & \\
\hline 24 &, 647 & 1,079 & 85,428 & & & & & & \\
\hline 25 &, 627 & 1,045 & 86,473 & & & & & & \\
\hline 26 &, 593 & ,989 & 87,462 & & & & & & \\
\hline 27 &, 579 &, 965 & 88,427 & & & & & & \\
\hline 28 &, 535 & ,891 & 89,318 & & & & & & \\
\hline 29 &, 518 &, 863 & 90,181 & & & & & & \\
\hline 30 & ,492 & ,820 & 91,000 & & & & & & \\
\hline 31 &, 423 & ,705 & 91,706 & & & & & & \\
\hline 32 & ,403 &, 671 & 92,377 & & & & & & \\
\hline 33 & ,382 &, 636 & 93,013 & & & & & & \\
\hline 34 &, 361 &, 601 & 93,614 & & & & & & \\
\hline 35 &, 347 &, 578 & 94,192 & & & & & & \\
\hline 36 & ,321 &, 535 & 94,727 & & & & & & \\
\hline 37 & ,300 & ,499 & 95,226 & & & & & & \\
\hline 38 &, 276 &, 460 & 95,687 & & & & & & \\
\hline 39 & ,271 &, 452 & 96,139 & & & & & & \\
\hline 40 &, 260 & ,433 & 96,572 & & & & & & \\
\hline 41 &, 247 &, 412 & 96,984 & & & & & & \\
\hline 42 & ,212 &, 353 & 97,336 & & & & & & \\
\hline 43 & 203 & ,339 & 97,676 & & & & & & \\
\hline 44 & ,184 & ,306 & 97,982 & & & & & & \\
\hline 45 &, 170 & ,283 & 98,265 & & & & & & \\
\hline 46 &, 154 &, 257 & 98,522 & & & & & & \\
\hline 47 &, 148 &, 247 & 98,769 & & & & & & \\
\hline 48 & ,128 & ,213 & 98,982 & & & & & & \\
\hline 49 & 109 & ,182 & 99,164 & & & & & & \\
\hline 50 &, 104 &, 173 & 99,337 & & & & & & \\
\hline 51 & ,077 & , 129 & 99,466 & & & & & & \\
\hline 52 & ,068 &, 113 & 99,578 & & & & & & \\
\hline 53 & ,062 & ,103 & 99,681 & & & & & & \\
\hline 54 & ,057 & ,095 & 99,776 & & & & & & \\
\hline 55 &, 054 & ,091 & 99,867 & & & & & & \\
\hline 56 &, 039 &, 065 & 99,932 & & & & & & \\
\hline
\end{tabular}




\begin{tabular}{|c|c|c|c|c|c|c|c|c|c|}
\hline \multirow[b]{2}{*}{ 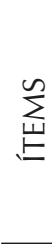 } & \multicolumn{3}{|c|}{ Autovalores iniciales } & \multicolumn{3}{|c|}{$\begin{array}{l}\text { Sumas de extracción } \\
\text { de cargas al cuadrado }\end{array}$} & \multicolumn{3}{|c|}{$\begin{array}{c}\text { Sumas de rotación } \\
\text { de cargas al cuadrado }\end{array}$} \\
\hline & $\frac{\pi}{0}$ & 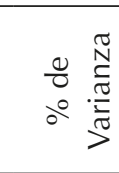 & 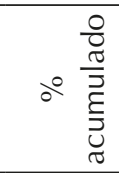 & 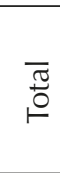 & 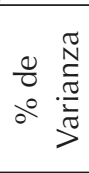 & 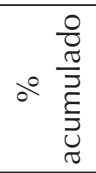 & 胥 & $\begin{array}{ll}\frac{\pi}{N} \\
\frac{\pi}{0} \\
0 \\
0\end{array}$ & 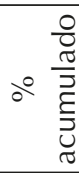 \\
\hline 57 & 021 & ,034 & 99,966 & & & & & & \\
\hline 58 & ,013 &, 021 & 99,987 & & & & & & \\
\hline 59 & ,005 &, 009 & 99,996 & & & & & & \\
\hline
\end{tabular}

Extraction Method: Principal Component Analysis.

\section{Descripción de los factores en función de la Teoría de la Acción Planificada}

La representación gráfica de los seis factores y su relación con la Teoría de la Acción Planificada (Steinmetz et al., 2016, p. 220) quedan reflejadas en la siguiente Figura, que valida el cuestionario y su contenido (Figura 1).

Esta Figura presenta, por un lado, la configuración de las variables externas del sujeto de las que depende su conducta. Estas variables -demográficas, de expectativas profesionales y de rasgos de personalidadafectan a cómo el sujeto procesa la información de la que dispone para elaborar juicios y tomar decisiones, es decir, para actuar. Asimismo, estas variables influyen en las Creencias/convicciones de un sujeto. La segunda columna hace referencia a las Creencias/convicciones del sujeto, que engloban sus ideas, valores, opiniones, estereotipos, ... Toda esta información es fundamental porque determina lo que el sujeto cree acerca de sus acciones -si serán o no beneficiosas-, si están a la altura de lo que esperan sus referentes sociales o de si posee las habilidades necesarias para poder llevarlas a cabo a través de sus comportamientos. Es decir, las Creencias/convicciones de un sujeto influyen en las Actitudes, Normas subjetivas y Habilidades de un sujeto determinado. La tercera columna representa las Actitudes, Normas subjetivas y Habilidades de los sujetos. Las Actitudes son la predisposición a actuar de una determinada manera. Las Normas subjetivas hacen referencia a la percepción que tiene el sujeto de lo que otras personas esperan de él. Y las habilidades son las competencias/capacidades que posee para realizar alguna acción. Estos tres aspectos explican la Intención de conducta de una persona e influ- 
yen en sus decisiones sobre si llevar a cabo o no una Conducta. La cuarta columna hace referencia a la Intención de conducta, entendida como la decisión de un sujeto para realizar o no una determinada conducta y, por tanto, influye directamente en la Conducta. Por último, la quinta columna representa la propia Conducta del sujeto, es decir, la realización efectiva de un determinado acto. Por ello, conocer las Creencias/ convicciones, las Actitudes, las Normas subjetivas, las Habilidades y las Intenciones de conducta de un sujeto nos pueden ayudar a determinar sus Conductas futuras.

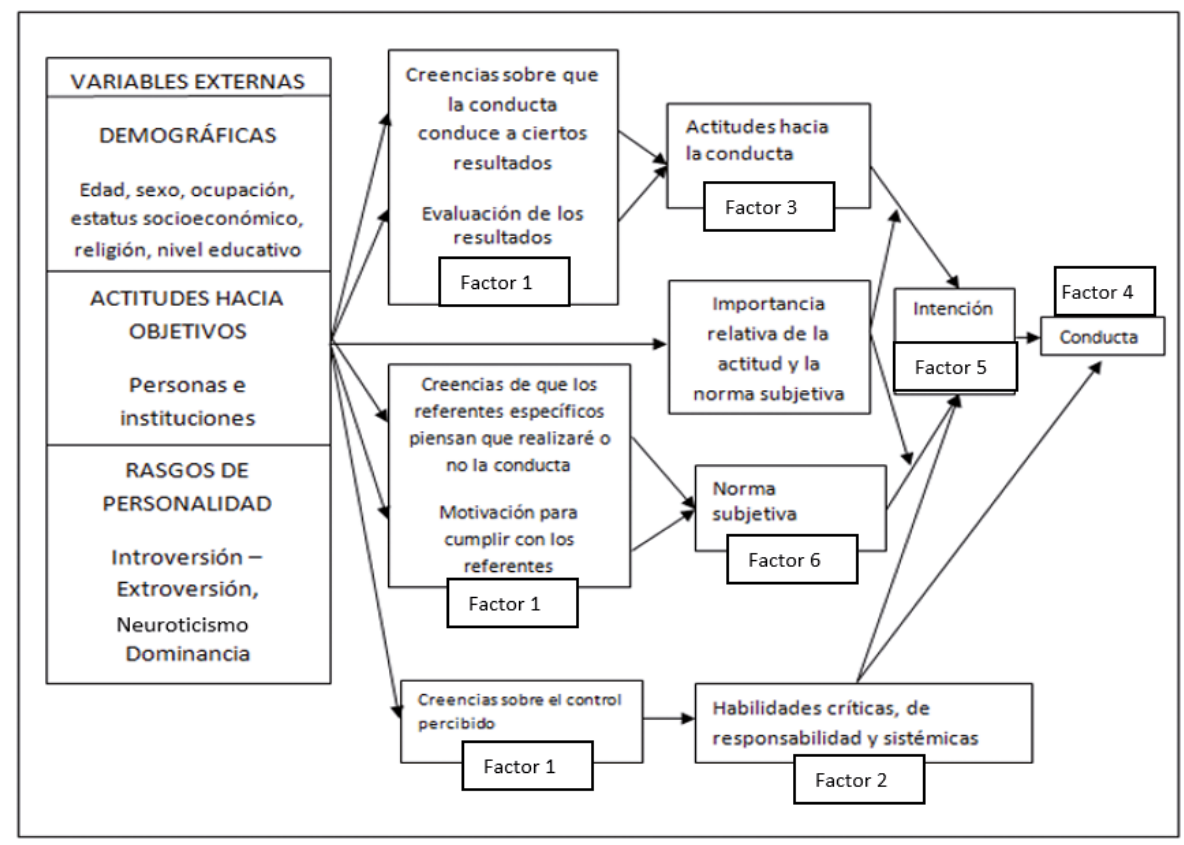

Figura 1. Factores en función de la Teoría de la Acción Planificada.

FACTOR 1: Creencias del profesorado de Educación Primaria (ítems: 53, 52, 43, 32, 6, 5, 65, 25, 58 y 44).

FACTOR 2: Habilidades del profesorado (ítems: 61, 28, 62, 33, 60, 29, $46,39,41,64,21,36,35,57,51,30$ y 34$)$.

FACTOR 3: Actitudes del profesorado (ítems: 37, 31, 63, 47, 40, 15, 18, 38, 27 y 45$)$.

FACTOR 4: Conductas del profesorado (ítems: 17, 3, 10, 1, 54, 2, 59, 55, 4, 20 y 9$)$. 
FACTOR 5: Intenciones de conducta del profesorado (ítems: 22, 12, 26, 56 y 19$)$.

FACTOR 6: Normas subjetivas del profesorado (ítems: 14, 24, 23, 13, 48, 42 y 16$)$.

\section{Discusión}

Las competencias docentes del profesorado determinan la calidad del sistema educativo. Por ello, el análisis de cuáles de estas competencias posee -o cree poseer- el profesorado de Educación Primaria debe ser un primer paso para detectar posibles deficiencias formativas y así poder implementar programas de formación continua o modificar los planes de estudio del Título de Maestro.

Para analizar las Competencias docentes existen diferentes cuestionarios. El cuestionario de Fernández-Berrueco y Sánchez-Tarazaga (2014) divide las competencias en función de los 4 pilares del Informe Delors: competencias científicas (Saber), competencias metodológicas (Saber hacer), competencias sociales (Saber estar) y competencias personales (Saber ser). El cuestionario de Mena y García-Sanz (2017) se centra en la labor del docente en la atención a la diversidad y se divide en las siguientes competencias: Académicas, Didácticas, Organizativas, Comunicativas, Integradoras y Evaluadoras. El cuestionario de Bujanda (2017) pone su foco de atención en la Formación Profesional y presenta la siguiente clasificación competencial: Científica, Intra e Interpersonal, Didáctica, Organizativas y de Gestión del centro, Gestión de grupos de alumnos y Trabajo en equipo. El cuestionario de Fernández et al. (2016) evalúa las carencias del profesorado en las siguientes competencias: Instrumentales, Conocimiento y metodológicas, Evaluativas e Interpersonales. Y, por último, el cuestionario de Valdemoros y Lucas (2014) define el perfil competencial del profesorado de Educación Primaria en función de la opinión del alumnado y clasifica las competencias en: Saber hacer, Afectivo-emocionales, Instrumentales y espíritu formativo y Personalidad docente.

Todos ellos presentan resultados muy interesantes pero no nos ayudan a predecir las intenciones de conductas ni las conductas del profesorado, quedándose simplemente en el diagnóstico de actitudes y creencias, es decir, en el aspecto axiológico. Por el contrario, el Mode- 
lo de Acción Planificada nos permite dar un paso más allá y conocer las intenciones que Ilevan a los docentes a actuar de una determinada manera. Desde este punto de vista, el Cuestionario de autopercepción sobre las Competencias docentes del profesorado de Educación Primaria tiene la virtualidad de evaluar las expectativas del propio docente sobre su intención de conducta y su conducta concreta, por lo que nos permite evaluar los comportamiento en función de sus creencias, habilidades, actitudes y normas subjetivas, es decir, lo que los demás esperan de ellos. Todo ello, nos permite tener una visión de conjunto que nos ayuda a comprender la tarea docente y a diagnosticar las posibles carencias formativas y/o malas praxis pedagógicas. Por ello, pensamos que puede aportar un valor añadido a la investigación sobre las competencias del profesorado.

\section{Conclusiones}

El cuestionario validado puede ayudar a conocer el perfil competencial del profesorado de Educación Primaria y orientar las políticas de formación docente. A través de sus preguntas se evalúa la autopercepción del profesorado acerca de sus competencias profesionales, atendiendo a las Creencias, Actitudes y Habilidades del profesorado. Además, tiene en cuenta la influencia de los compañeros y/o de la sociedad (Normas subjetivas) e intenta predecir las Intenciones de conducta y las Conductas de los docentes en su quehacer profesional. De esta manera, se da respuesta a las demandas de las políticas educativas de la OCDE (2015) y del MECD (2015) donde se reclama definir el perfil competencial del profesorado para, posteriormente, adaptar sus procesos de formación inicial y continua.

\section{Referencias}

Ajzen, I. y Fishbein, M. (1980). Understanding attitudes and predicting social behavior. Englewood Cliffs: Prentice Hall.

Armengol, C., Castro, D., Jariot, M., Massot, M. y Sala, J. (2011). El Practicum en el Espacio Europeo de Educación Superior (EEES): mapa de competencias del profesional de la educación. Revista de Educación, 354, 71-98.

Barbour, R. (2013). Los grupos de discusión en Investigación Cualitativa. Madrid: Morata. 
López Luján, E. y Sanz Ponce, R. (2021). Construcción y validación del cuestionario de autopercepción sobre las Competencias docentes del profesorado. Educatio Siglo XXI, 39(3), 157-186.

Bolívar, R.M. (2019). Investigar la práctica pedagógica en la formación inicial de maestros. Pedagogía y Saberes, 51, 9-22.

Bujanda, E. (2017). Diseño de un cuestionario de competencias docentes del profesorado de Formación Profesional de la familia Servicios Socioculturales y a la Comunidad. RES: Revista de Educación Social, 24, 1163-1178.

Consejería de Educación de la Junta de Castilla y León (2012). Modelo de Competencias Profesionales del Profesorado. Castilla y León: Dirección General de Calidad, Innovación y Formación del Profesorado.

Day, C. (2019). What is teaching about? Professionalism and the limitations of standards and competences. European Journal of Education, 54(3), 315-318.

Escámez-Marsilla, J.I. (2018). Las percepciones de las capacidades para la gestión de la sostenibilidad del estudiantado del Grado de ADE de la UPV y la UCV: Análisis comparado. Tesis doctoral no publicada. Universidad Politécnica de Valencia, España.

Fernández, Mª., Rodríguez, J.M. y Fernández, F.J. (2016). Evaluación de competencias docentes del profesorado para la detección de necesidades formativas. Bordón, 68(2), 85-101.

Fernández-Berrueco, R. y Sánchez-Tarazaga, L. (2014). Competencias docentes en Secundaria. Análisis de perfiles de profesorado. RELIEVE, v. 20(1), 1-20.

Galvis, R.V. (2007). De un perfil docente tradicional a un perfil docente basado en competencias. Acción Pedagógica, 16, 48-57.

Hargreaves, A. y Fullan, M. (2014). Capital profesional. Madrid: Morata.

Hattie, J. (2017). Aprendizaje visible" para profesores. Maximizando el impacto en el aprendizaje. Madrid: Paraninfo.

MECD (2015). Informe 2015 sobre el estado del Sistema Educativo. Curso 2013_2014. Madrid: Secretaria General Técnica.

Meirieu, P. (2019). Riquezas y límtes del enfoque por "competencias" del ejercicio de la profesión docente hoy. Pedagogía y Saberes, 50, 97-108.

Mena, R. y García-Sanz, Ma.P. (2017). Cuestionario para la evaluación de competencias del profesorado en atención a la diversidad (CECPAD). Murcia: Universidad de Murcia.

Morales, P., Urosa, B., y Blanco, A. (2003). Construcción de escalas de actitudes tipo Likert. Madrid: La Muralla.

Mourshed, M., Chijioke, C. y Barber, M. (2012). Cómo continúan mejorando los sistemas educativos de mayor progreso en el mundo. Chile: McKinsey.

OCDE (2015). Política educativa en perspectiva 2015. Hacer posible las reformas. España: Santillana.

Orden ECl/3854/2007, de 27 de diciembre, por la que se establecen los requisitos para la verificación de los títulos universitarios oficiales que habiliten para el ejercicio de la profesión de Maestro en Educación Infantil, BOE, n 312, de 29 de diciembre de 2007, pp. 53735-53738.

Perrenoud, P. (2010). Diez nuevas competencias para enseñar. Barcelona: Graó.

Prats, E. (2016). La formación inicial docente entre profesionalismo y vías alternativas: mirada internacional. Bordon, 68(2), 19-33.

Steinmetz, H., Knappstein, M., Ajzen, I., Schmidt, P. \& Kabst, R. (2016). How Effecti- 
ve are Behavior Change Interventions Based on the Theory of Planned Behavior? A Three-Level Meta-Analysis. Zeitschrift für Psychologie, 224, (3), 216-233.

Valdemoros, M.A. y Lucas, B. (2014). Competencias que configuran el perfil del docente de primaria: análisis de la opinión del alumnado de Grado en Educación Primaria. Aula Abierta, 42 (1), 53-60.

\section{ANEXO: Cuestionario Competencias docentes del profesorado de Educación Primaria}

Edad: Sexo: Tienes Hijos: Años de experiencia
Tipo de centro
$\square$ Menor de 5 años
口 Público
$\square$ Entre 6 y 15 años
$\square$ Concertado
口 Entre 16 y 25 años
口 Más de 26 años

\begin{tabular}{|c|c|c|c|c|c|c|}
\hline & Como profesor... & & & & & \\
\hline 1 & $\begin{array}{l}\text { Domino los contenidos de las diferentes áreas de cono- } \\
\text { cimiento }\end{array}$ & 1 & 2 & 3 & & 5 \\
\hline 2 & $\begin{array}{l}\text { Utilizo las estrategias y técnicas didácticas para la ense- } \\
\text { ñanza de las diferentes áreas }\end{array}$ & 1 & 2 & 3 & 4 & 5 \\
\hline 3 & $\begin{array}{l}\text { Utilizo estrategias específicas para la organización y } \\
\text { diseño de situaciones de aprendizaje }\end{array}$ & 1 & 2 & 3 & 4 & 5 \\
\hline 4 & $\begin{array}{l}\text { Utilizo métodos para implicar al alumnado en los proce- } \\
\text { sos de su aprendizaje y trabajo }\end{array}$ & 1 & 2 & 3 & 4 & 5 \\
\hline 5 & $\begin{array}{l}\text { No estoy preparado para resolver o gestionar los conflic- } \\
\text { tos en el aula o en el centro }\end{array}$ & 1 & 2 & 3 & 4 & 5 \\
\hline 6 & $\begin{array}{l}\text { No necesito conocer técnicas novedosas de evaluación } \\
\text { para conocer los aprendizajes del alumnado }\end{array}$ & 1 & 2 & 3 & 4 & 5 \\
\hline 7 & $\begin{array}{l}\text { Es necesario que todo el profesorado conozca el Proyec- } \\
\text { to Educativo del Centro en el que trabaja }\end{array}$ & 1 & 2 & 3 & 4 & 5 \\
\hline 8 & $\begin{array}{l}\text { Cumplo los derechos y deberes de los miembros de la } \\
\text { Comunidad Educativa }\end{array}$ & 1 & 2 & 3 & 4 & 5 \\
\hline 9 & $\begin{array}{l}\text { Son innecesarios los planes y programas específicos de } \\
\text { la Comunidad Valenciana (PAT, Compensatoria, ...) que } \\
\text { el Centro tiene en funcionamiento para evitar el fracaso } \\
\text { escolar }\end{array}$ & 1 & 2 & 3 & 4 & 5 \\
\hline 10 & $\begin{array}{l}\text { Las características psicoevolutivas y del desarrollo de } \\
\text { la identidad del alumno son necesarias en el proceso } \\
\text { educativo }\end{array}$ & 1 & 2 & 3 & 4 & 5 \\
\hline 11 & $\begin{array}{l}\text { Mis compañeros creen que es necesario atender a las } \\
\text { diferencias en los ritmos de aprendizaje }\end{array}$ & 1 & 2 & 3 & 4 & 5 \\
\hline
\end{tabular}


López Luján, E. y Sanz Ponce, R. (2021). Construcción y validación del cuestionario de autopercepción sobre las Competencias docentes del profesorado. Educatio Siglo XXI, 39(3), 157-186.

\section{Como profesor...}

12 La formación de la libertad personal y el pensamiento crítico del alumnado no están en mis funciones como $\quad \begin{array}{llllll}1 & 2 & 3 & 4 & 5\end{array}$ docente

13 Soy consciente de que la convivencia en el centro y en sus aulas reflejan las tensiones sociales

$\begin{array}{lllll}1 & 2 & 3 & 4 & 5\end{array}$

14 Explico con claridad los contenidos de las áreas que imparto

$\begin{array}{lllll}1 & 2 & 3 & 4 & 5\end{array}$

15 Reflexiono y me evalúo a partir de la propia práctica docente

$\begin{array}{lllll}1 & 2 & 3 & 4 & 5\end{array}$

16 No utilizo las habilidades para argumentar y debatir

17 Escucho las preguntas e interrogantes que me formulan los estudiantes

$\begin{array}{lllll}1 & 2 & 3 & 4 & 5\end{array}$

$\begin{array}{lllll}1 & 2 & 3 & 4 & 5\end{array}$

18 Analizo críticamente los contenidos de las diferentes áreas

$\begin{array}{lllll}1 & 2 & 3 & 4 & 5\end{array}$

19 No pierdo el tiempo en analizar críticamente los acontecimientos que se producen en la sociedad

$\begin{array}{lllll}1 & 2 & 3 & 4 & 5\end{array}$

20 Las habilidades para conducir el diálogo de los estudiantes en el aula son una necesidad docente

21 Gestionar adecuadamente el tiempo y los recursos del aula mejoran los resultados académicos

22 No organizo a los estudiantes para que trabajen en grupo

23 No me anticipo a los problemas de aprendizaje y prevenirlos

24 Me corresponde establecer las normas de funcionamiento y disciplina en el aula

25 Identifico a mis estudiantes también como generadores de contenidos de aprendizaje

26 Genero un ambiente en el que las diferencias personales y culturales son percibidas como enriquecimiento $\quad \begin{array}{llllll}1 & 2 & 3 & 4 & 5\end{array}$ mutuo

27 Observo e interpreto las emociones y/o sentimientos de los estudiantes

28 Me es difícil la relación con los compañeros, los alumnos y las familias de los alumnos/as

29 No es mi función observar e interpretar adecuadamente

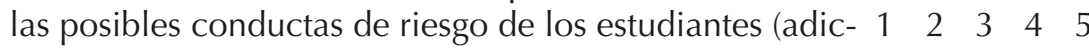
ciones, maltrato, ...)

30 Sé motivar a los alumnos/as para el aprendizaje $\quad \begin{array}{lllll}1 & 2 & 3 & 4 & 5\end{array}$

31 Me responsabilizo del aprendizaje del alumnado $\quad \begin{array}{llllll}1 & 2 & 3 & 4 & 5\end{array}$ 


\section{Como profesor...}

$\begin{array}{lllllll}32 & \text { Busco formación permanente en las diferentes áreas que } & 1 & 2 & 3 & 4 & 5\end{array}$ imparto

33 Me implico en los aspectos de innovación de la enseñanza

34 No estoy comprometido con la gestión de la diversidad cultural y personal de los alumnos/as

35 Estoy dispuesto a trabajar en equipo con otros profesores/as

36 Estoy dispuesto a adaptar los contenidos a los diferentes ritmos de aprendizaje de los alumnos/as

37 No me siento comprometido en la colaboración con el Equipo Directivo del Centro

38 Defino la dimensión educativa como tarea de mi labor docente

$\begin{array}{lllllll}39 & \text { La democracia es un valor que hay que salvaguardar } & 1 & 2 & 3 & 4 & 5\end{array}$

40 No es función mía promover en los estudiantes los valores de la ética civil: la libertad, la igualdad, la solidari- $\quad \begin{array}{llllll}1 & 2 & 3 & 4 & 5\end{array}$ dad, la justicia, la tolerancia, la responsabilidad y la paz

41 No considero necesaria la enseñanza de los Derechos Humanos

42 Respeto al alumno/a

43 Fomento la autoestima del alumnado

44 La diversidad cultural del alumnado distorsiona el funcionamiento del aula

45 Rechazo los prejuicios, el racismo y la discriminación $\quad \begin{array}{lllll}1 & 2 & 3 & 4 & 5\end{array}$

46 Identifico la participación del alumnado en el centro escolar como un aprendizaje para la futura participación $\quad 1 \quad 2 \quad 2 \quad 3 \quad 4 \quad 5$ en la sociedad civil

47 No veo necesario afrontar los deberes y las cuestiones éticas de la profesión docente

48 Es una pérdida de tiempo la educación para la sostenibilidad

49 Estimo el desarrollo de los conocimientos de las diferentes áreas y su investigación

50 No me gusta la profesión docente

51 La evaluación del aprendizaje de los alumnos tiene que ser igual para todos

52 Busco a iniciativas para la formación continua en aspectos metodológicos

53 No creo necesario el uso habitual de recursos TIC y apps con fines pedagógicos 


\section{Como profesor...}

54 Informo a los padres/madres y hago lo posible por impli- $\begin{array}{lllll}1 & 2 & 3 & 4 & 5\end{array}$ carles en el aprendizaje de sus hijas/os

55 Coopero y trabajo en equipo con los compañeros para poner en marcha proyectos y programas del Centro

56 Gestiono los conflictos según lo establecido en el Plan de Convivencia e Igualdad y los protocolos del RRI

57 Preparo las actividades como profesor atendiendo a la diversidad de capacidades y culturas de los estudiantes

58 Mis comportamientos como docente son indiferentes para orientar las conductas del alumnado

59 Considero fundamental tener iniciativa como profesional de la docencia

60 No es asunto mío que el alumnado adopte pensamientos y decisiones por él mismo 
